\title{
A RESPONSE TO PROFESSORS MEYER, OHLIN AND LORITE ESCORIHUELA
}

\author{
Pierre-Hugues Verdier* and Erik Voetent
}

We thank Professors Ingrid Wuerth, Karen Knop, Harlan Cohen, and the AJIL Unbound team for organizing this colloquium on our recent article, Precedent, Compliance and Change in Customary International Law: An Explanatory Theory. ${ }^{1}$ In their respective contributions, Professors Meyer, Ohlin and Lorite Escorihuela comment on numerous aspects of our theory. While we cannot systematically address all comments in this short reply, we hope to respond to the more salient points raised by each contributor.

\section{Professor Meyer's Response}

Professor Meyer asks whether our theory overstates the differences between treaties and customary international law (CIL). ${ }^{2}$ He argues that whether specific international law rules are sustained by direct reciprocity does not depend on their status as treaties or CIL but on whether "reciprocal non-compliance can be targeted at a violating state."

Clearly, the condition described by Professor Meyer must be met for reciprocity to be a viable enforcement mechanism. A prohibition on torture cannot credibly be enforced by torturing a state's own citizens in response to the other state's violation. However, there are many norms that could theoretically be enforced through reciprocity but are not. We argue that the CIL status of a norm reflects a common understanding that cooperation in equilibrium arises because states generally and consistently practice a behavior out of a sense of legal obligation. This differs fundamentally from a common understanding that tit-for-tat reciprocity governs cooperation.

In a separate article published in International Studies Quarterly, we document this extensively with regard to foreign state immunity. For example, when a Belgian civil court in 1903 allowed a company to pursue a case against the Netherlands, the Netherlands could have responded by instructing its courts to allow cases against Belgium. This type of equilibrium behavior is common in international affairs and international law. Instead, the Netherlands continued applying absolute immunity to all states until several decades later. ${ }^{3}$ Our claim is that the Netherlands may have done so because it feared that selectively departing from absolute immunity would be understood as abandoning the norm that absolute immunity is a general practice that states are legally obligated to follow. Yet, once most of its export partners adopted restrictive immunity, holding out was no longer

* Professor of Law, University of Virginia.

† Peter F. Krogh Associate Professor of Geopolitics and Justice in World Affairs, Georgetown University.

Originally published online 10 June 2015.

1 Pierre-Hugues Verdier \& Erik Voeten, Precedent, Compliance, and Change in Customary International Law: An Explanatory Theory, 108 AJIL 389, 390 (2014).

${ }^{2}$ Timothy Meyer, How Different are Treaties and Modern Customary International Law? A Response to Verdier and Voeten, 108 AJIL UNBOUND 240 (2015).

3 See Pierre-Hugues Verdier \& Erik Voeten, How Does Customary International Law Change? The Case of State Immunity, 59 INT’L STUD. Q. (forthcoming 2015). 
worth it. This pattern holds more generally: states adopt a single position and tend to apply it consistently across foreign states. ${ }^{4}$

We see similar patterns in other CIL norms. Consider the norm that governments should not kill or physically harm the diplomats of other states. There is no doubt such a norm could be enforced by tit-for-tat reciprocity. Yet, once this norm has acquired CIL status (i.e., states commonly understand it as a CIL norm), a tit-for-tat response could be interpreted as a denial of this status, thus potentially undermining the regime. What we see instead is retaliation that takes slightly different forms, such as expelling diplomats or severing diplomatic ties. Similar logics apply to other CIL norms. The fact that Russia violated the territorial integrity of Ukraine does not entitle any other state to violate Russia's territorial integrity. ${ }^{5}$ Again, this is not because the norm of territorial integrity couldn't plausibly be sustained in this way. It was common historically to punish aggressor states with territorial losses, but this would not be consistent with the current status of territorial integrity as a CIL norm.

Our theory does not imply that reciprocity can never arise in the context of CIL rules. As Professor Meyer notes, national immunity statutes sometimes reserve this possibility. Importantly, the provisions he cites-although part of statutes that generally vest upon courts the authority to apply foreign state immunity-all designate the executive as the appropriate authority to apply reciprocity. This underlines the exceptional nature of this remedy and recognizes that using it has political implications, such as potentially undermining the CIL rule, which should be considered outside the normal course of the rule's application by courts. Further, statutes that purport to authorize reciprocity are rarely applied, as indicated by recent Chinese and Russian sources. ${ }^{6}$

Unlike CIL rules, the legal obligations created by treaties are understood to rest on reciprocity. Not only do these obligations apply only to states parties, they can also be terminated in response to a material breach. ${ }^{7}$ By contrast, a state cannot exit a CIL rule in response to a breach - the rule remains in force and prima facie applicable between the two states, except to the limited extent permitted by the law on countermeasures. Thus, the legal and institutional characteristics of treaties that facilitate direct reciprocity - such as procedural requirements, limits on permissible responses, and third-party dispute resolution — are not fortuitous, but they extend the logic of reciprocity that shapes common understandings of how treaty-based cooperation works.

To be sure, some treaties lack these characteristics, and some CIL rules benefit from dispute resolution. In that sense, our contrast of treaties and CIL relies on ideal-type characterization, with actual cases falling closer to one side or the other. Indeed, Professor Meyer notes that due to codification efforts and the proliferation of treaties, CIL and treaties are becoming increasingly intertwined. This may mean that the effectiveness of

\footnotetext{
${ }_{4}$ Professor Meyer cites instances of reciprocity in the context of diplomatic relations as a counter-example. However, reciprocity in this area often relates to privileges and immunities in excess of what is clearly required by law. This is consistent with the idea that recognizing a rule as CIL implies that it is prima facie applicable to all states, while "reciprocity is made to apply to concessions and privileges to which states are not entitled, or which they are not bound to grant, according to ordinary international law." Hersch Lauterpacht, The Problem of Jurisdictional Immunities of Foreign States, 1951 BRIT. Y.B. INT'L L. 220, 228. In some cases, states may want to respond in kind to clear violations of diplomatic law. As long as the rules were CIL, however, reciprocal responses ran the risk of undermining them. This may be one reason why states have chosen to codify this area.

${ }^{5}$ Except of course to the extent permitted by self-defense-but permitting self-defense by an attacked state does not amount to applying the primary rule prohibiting the use of force on the basis of reciprocity. We develop this point in Verdier \& Voeten, supra note 1 , at 431-32.

${ }^{6}$ Ekaterina Bykhovskaya, State Immunity in Russian Perspective 146 (2008) states that the relevant provision was never applied in the Soviet Union or post-1991 Russia. Chinese sources note disagreement among Chinese scholars as to the applicability of reciprocity to foreign state immunity, and provide no instances of its application. See, e.g., Huang Jin \& Ma Jingsheng, Immunities of States and their Property: The Practice of the People's Republic of China, 1 Hague Y.B. InT'L L. 163 (1988); Zhu Lijiang, State Immunity from Measures of Constraints for the Property of Foreign Central Banks: The Chinese Perspective, 6 CHINESE. J. INT'L L. 67 (2007). We discuss the practice of other countries in Verdier \& Voeten, supra note 3.

${ }^{7}$ Vienna Convention on the Law of Treaties art. 60. May 23, 1969, 1155 UNTS 331.
} 
some treaties-especially those that purport to create universal rules not subject to derogation, such as the prohibition on torture-may rest more on precedential concerns, like CIL, than on reciprocity or retaliation. ${ }^{8}$ States may also choose to codify CIL rules to prevent their erosion and to facilitate retaliation and reputational compliance mechanisms. ${ }^{9}$ As both Professors Meyer and Ohlin correctly point out, we cannot show that precedential concerns are more or less important overall than retaliation or reputation. We believe, however, that clarifying the mechanisms that shape compliance in each ideal-type provides a theoretical basis to understand less clear-cut cases.

\section{Professor Oblin's Response}

Professor Ohlin asks what happens to CIL in one-shot scenarios when long-term interests are muted or absent, for example where the state's survival is threatened or when a state believes that it is unlikely to benefit from future compliance by others with the same rule. Professor Ohlin is correct that, in both cases, our theory initially predicts noncompliance..$^{10}$ In the first case, this is unsurprising-precedential concerns may be an important consideration, but will not prevail when weightier interests are on the other side. In the second, precedential concerns are weak or nonexistent, and therefore easily outweighed by even modest benefits from breach. The state simply does not much value the rule, since it does not expect future benefits from its continued existence.

We would like to offer two additional thoughts on these scenarios. First, in areas of international relations where such situations commonly occur, CIL norms should be less likely to emerge in the first place, at least through the traditional "spontaneous" process of accumulation of consistent practice and opinio juris. Where CIL norms do emerge in such areas, it suggests that states value them sufficiently to produce compliance adequate to sustain the rule's existence. In the article, we suggest that powerful states that value a CIL rule may be willing to tolerate occasional defections by states that are marginal to the overall practice. In other cases, CIL norms in such areas — such as the modern CIL on the use of force-may arise out of a multilateral treaty regime rather than from the traditional process. ${ }^{11}$

Second, as Professor Ohlin acknowledges, our theory is descriptive rather than normative: it aims at explaining compliance and change in CIL rules, not at exploring whether there is a moral basis for states to follow CIL where self-interest points towards defection. In this sense, it differs from the normative account of rationality offered by Professor Ohlin, which explicitly engages the second question. ${ }^{12}$ This being said, we wish to emphasize that nothing in our theory requires that all relevant state interests be material in nature. States may prefer a rule to become or remain embedded in international society-and therefore care about the long-term effect of precedent-because of normative preferences. We return to this idea below.

\footnotetext{
8 See Verdier \& Voeten, supra note 1, at 426 n.200.

9 See Verdier \& Voeten, supra note 3 (discussing UN codification of foreign state immunity).

${ }^{10}$ Jens David Ohlin, Precedent and Custom: A Response to Verdier and Voeten, 108 AJIL UnBound 246 (2015).

${ }^{11}$ UN Charter arts. 2(4) and 51.

12 Jens David OHLin, The Assault On International LAW (2015). We recognize that our descriptive account inevitably sets aside normative questions of interest to many scholars, and we thank Professor Ohlin for offering thoughts on some of these questions in his response.
} 


\section{Professor Lorite Escoribuela's Response}

Professor Lorite Escorihuela directs two main critiques at our theory: first, that it is misguided, because it implicitly advances an ideologically-driven research program that is destructive of international law's normativity; second, that it is obvious, because it merely restates traditional CIL doctrine under a garb of social science. ${ }^{13}$ While we perceive some tension between these two critiques, we will nevertheless address each one in turn.

Professor Lorite Escorihuela alleges that our theory, by deploying a rational choice framework and social science methods to explain CIL, "completes the overall design of the originators of rational-choice scientism in international law," which implies "instrumentalizing rational-choice theorizing to delegitimate normative (legal or moral) talk at the international level." This argument misses the mark along several dimensions.

First, on a conceptual level, proposing a descriptive theory of a social practice does not amount to delegitimizing the normative talk that occurs within that practice. If true, this critique would prove far too much-do theories and empirical studies of voting behavior "delegitimize" normative debate in domestic politics? In many areas of social practice, actors engage in vigorous normative argument, but this tells us little about how the debate will unfold or which arguments will prevail. Much contemporary social science rests on the premise that social processes and outcomes can be explained by reference to empirically verifiable factors, including material interests, institutions, and sociological and psychological processes. While this approach is explanatory in nature, it does not necessarily involve disregarding or devaluing the normative dimension of the practice, as we develop further below. ${ }^{14}$

Second, Professor Lorite Escorihuela mistakenly situates all uses of rational choice reasoning-and apparently all "explanatory and predictive propositions" about international law-as extensions of Goldsmith and Posner's well-known critique. ${ }^{15}$ For better or worse, international law has long faced a special burden of explanation and justification-skeptics like to cite Thucydides and Machiavelli as examples of a proto-realist approach, ${ }^{16}$ and Austin famously described international law as mere "positive morality." 17 More to the point, interest in understanding the processes through which international law affects state behavior is not limited to

13 Alejandro Lorite Escorihuela, The Translation of Common Sense, 108 AJIL UnBound 250 (2015).

${ }^{14} \mathrm{It}$ is also noteworthy that unlike most modern legal sources, the norms governing CIL formation explicitly incorporate reference to the actual practice and beliefs of states. The search for CIL thus has an empirical component, even in its own normative terms. In this sense, CIL is indeed "plausibly interested in describing the world." The fact that CIL explicitly stakes its claim to normativity on consistency with facts about the world makes descriptive investigation important to international lawyers, not just social scientists.

15 Jack L. Goldsmith \& Eric A. Posner, A Theory of Customary International Law, 66 U. CHI. L. Rev. 1113 (1999); JACK L. GOLDSMITH $\&$ ERIC A. POSNER, THE LIMITS OF INTERNATIONAL LAW (2005).

16 See, e.g., GOLDSMith \& Posner, $\underline{i d .}$ at 167.

${ }^{17}$ John Austin, The Province of Jurisprudence Determined 146-47 (1832). 
skeptics. ${ }^{18}$ In recent years, numerous political scientists have developed theoretical accounts and empirical studies in areas as diverse as territorial dispute settlement, ${ }^{19}$ trade, ${ }^{20}$ investment, ${ }^{21}$ and human rights ${ }^{22}$ —with results that rarely follow the Manichean divide Professor Lorite Escorihuela has in mind. ${ }^{23}$

Third, our theory not only concludes that CIL indeed shapes state behavior, but it is also consistent with much of traditional CIL doctrine. In this, it departs from rational choice accounts such as Goldsmith and Posner's (which attacks perceived inconsistencies and absurdities in CIL doctrine, and concludes that CIL has no independent impact on state behavior) and Guzman's (which concludes that many aspects of CIL doctrine are simply nonsensical). Nevertheless, Professor Lorite Escorihuela appears to argue that because skeptics have used rational choice reasoning and social science tools in the past, their further use inevitably further corrodes international law. This argument embeds several heroic assumptions, including that the background condition is one of general acceptance of international law's normativity and impact; that the use of social science tools is uniquely potent in undermining this condition; and that these tools are so tainted by skepticism that the method is the message, regardless of the actual conclusions reached. Professor Lorite Escorihuela provides no support for any of these claims, which we believe will strike many readers as implausible.

Professor Lorite Escorihuela's second critique is that our theory is merely "the translation of common sense," so that we end up "reinventing the wheel" by providing a social scientific explanation for well-understood features of the traditional doctrinal account. While it is true that we devote several pages to arguing that our theory is consistent with traditional CIL doctrine, this critique both misapprehends the purpose of this exercise and misses other central insights offered by our account.

First, the perceived inconsistencies in traditional CIL doctrine are often invoked to question the coherence, usefulness or legitimacy of CIL. This is true not only of the rational choice critics of CIL, but also of virtually all existing accounts, including mainstream scholarship, conservative attacks, and radical critiques. Thus, our

18 See generally Gregory Shaffer \& Tom Ginsburg, The Empirical Turn in International Legal Scholarship, 106 AJIL 1 (2012); Emilie M. Hafner-Burton et al., Political Science Research on International Law: The State of the Field, 106 AJIL 47 (2012); INTERDISCIPLINARY PERSPECTIVES ON INTERNATIONAL LAW AND InTERNATIONAL RELATiONS (Jeffrey L. Dunoff \& Mark A. Pollack eds., 2013). Professor Lorite Escorihuela's claim that interest in explaining CIL from a political science perspective "would not exist without Jack Goldsmith and Eric Posner's 1999 'rational-choice' intervention" is speculative, and in our view untenable in light of the growing interest in interdisciplinary approaches that emerged as early as the late 1980s. See, e.g., Kenneth W. Abbott, Modern International Relations Theory: A Prospectus for International Lanyers, 14 YALE J. INT'L L. 335 (1989); Anne-Marie Slaughter et al, International Law and International Relations Theory: A New Generation of Interdisciplinary Scholarship, 92 AJIL 367 (1998).

${ }_{19}$ See e.g. Paul K. Huth, Sarah E. Croco \& Benjamin J. Appel, Does International Law Promote the Peaceful Settlement of International Disputes? Evidence from the Study of Territorial Conflicts since 1945, 105 AM. POL. SCI. REv. 415 (2011).

20 See, e.g., Krzysztof J. Pelc, Constraining Coercion? Legitimacy and Its Role in US Trade Policy, 1975-2000, 64 INT'L ORG. 64 (2010).

21 See, e.g., Todd Allee \& Clint Peinhardt, Contingent Credibility: The Impact of Investment Treaty Violations on Foreign Direct Investment, 65 INT'L ORG. 401 (2011).

22 See, e.g., Beth A. Simmons, Mobilizing for Human Rights: InTERnational LaW in Domestic Politics (2009).

23 One might try to salvage this critique by distinguishing "good" IL-IR scholarship from "bad" rational choice accounts—presumably including our article- that undermine the normativity of international law. We doubt that Professor Lorite Escorihuela has such a distinction in mind. In any event, this argument would be untenable. First, virtually all recent IL-IR work incorporates some rational choice considerations in constructing accounts of specific areas or phenomena. For example, SimmONs, $\underline{i d}$., argues that because of lack of reciprocity and incentives to enforce, it does not seem rational for states to ratify and comply with HR treaties, thus setting up the puzzle she sets up to solve - the same move Professor Escorihuela criticizes in our analysis. Second, while our theory is articulated in a rational choice framework, it also recognizes that central role of shared legal understandings of CIL in shaping cooperation, and allows that states and other actors can be driven by normative preferences. (We return to these points below.) Thus, like much contemporary IL-IR scholarship, it sets out to explain a specific aspect of international law by developing a mid-level theory that incorporates relevant insights from cognate theoretical perspectives where appropriate. It is unclear exactly what would make it fall on the wrong side of the alleged line. Third, even IL-IR scholarship that does not rest on rational choice assumptions, such as studies of international norm diffusion, often draws on non-legal factors-like the density of cultural links between countries-in pursuit of an "explanatory and predictive" project. See, e.g., Katerina Linos, The Democratic Foundations OF POLICy Diffusion (2013). 
argument that central features of CIL doctrine-including the ones other writers have found most puzzlingare in fact consistent with a plausible descriptive account of the underlying social processes is not as obvious as Professor Lorite Escorihuela suggests.

More generally, one of our objectives was to develop a theory that rests on social science premises but, unlike prior such accounts, takes seriously the views of international lawyers as to how CIL works. Indeed, a central claim of our theory is that CIL differs from other forms of international cooperation because characterizing a rule as CIL (rather than, say, "treaty," "comity" or "morality") invokes common understandings about how the rule is to be applied, the consequences of breach, and the possibility of change. These understandings do not come from nowhere- they arise for the actors' recognition of the normativity of CIL and its implications for expected behavior. Thus, our theory does recognize, as one of its central claims, a distinction between "what is really law and what is something else."

Second, our theory introduces several new insights about CIL. Indeed, our central argument—which goes completely unnoticed in Professor Lorite Escorihuela's critique-relates to patterns of change in CIL. Our theory explains how change begins and diffuses among states, based on their preferences and their expectations about the future behavior of others. To do so, it draws on political science and sociology scholarship that has not featured prominently in prior accounts. ${ }^{24}$ By contrast with traditional scholarship, which often suggests that there is a single correct answer as to the content of CIL, our account emphasizes that CIL rules are embedded in a continuous process of evaluation and change. Importantly, nothing in our account supposes that these choices rest only on material interests. While our state immunity example emphasizes such interests, we recognize that states may perceive a long-term interest in upholding CIL rules-such as those on human rights or the use of force-due to normative convictions.

Finally, Professor Lorite Escorihuela argues that our theory is tautological, insofar as we allegedly set up the examples we provide so that their outcomes are "axiomatically true." This critique misconstrues the purpose of our article: we present a theoretical account accompanied by illustrative examples, not a systematic empirical test of that theory. Our aim is to propose an internally consistent account from which observable implications for specific cases can be derived, tested, and compared to alternative theoretical predictions.

In our related work on foreign state immunity, we derive several observable implications of our theory for the shift from absolute to restrictive immunity and test them through quantitative and qualitative analysis. ${ }^{25} \mathrm{We}$ find that states became more likely to switch as more of their own export destinations switched, consistently with our hypothesis on the role of precedential concerns. This finding survives controlling for other plausible explanations, including concurrent normative changes in the notion of sovereignty. In our AJIL article, we find qualitatively that many aspects of traditional CIL doctrine-the self-understanding of lawyers as to how the process works - are more consistent with our theory than with prior rational choice accounts. ${ }^{26}$ This is another element of evidence. Our theory can generate observable implications for other cases, which can-and should - be tested empirically. Indeed, a legitimate criticism of existing social science-based theories of CIL is the lack of systematic empirical testing. In this article and our related work, we take a first step to remedy this shortcoming.

24 See Thomas C. Schelling, Micromotives And Macrobehavior (1978); Mark Granovetter, Threshold Models of Collective Behavior, 83 Aм. J. Soc. 1420 (1978); Thomas C. Schelling, Dynamic Models of Segregation, 1 J. Mathematical Soc. 143 (1971).

${ }^{25}$ Verdier \& Voeten, supra note 3.

26 Verdier \& Voeten, supra note 1. 